\title{
Absent septal q wave: a marker of the effects of abnormal activation pattern on left ventricular diastolic function
}

Han B Xiao, Derek G Gibson

Cardiac Department, Royal Brompton National Heart and Lung Hospital, London D G Gibson Correspondence to: Dr Derek G Gibson, Cardiac Department, Royal Cardiac Department, Royal Brompton National Heart and Lung Hospital, Sydne Accepted for publication 8 November 1993

\begin{abstract}
Objective-To investigate the possible mechanical associations of the presence or absence of the septal $q$ wave.

Study design-Retrospective and prospective study of 63 patients with various left ventricular diseases and 10 controls by electrocardiography, echocardiography, and pulsed Doppler recordings.

Setting-Tertiary cardiac referral centre. Patients-73 subjects were studied. 26 had absent septal $q$ waves and a QRS duration $<120 \mathrm{~ms}, 25$ had classic left bundle branch block, and the rest had a normal electrocardiogram. Pathologically, 34 had left ventricular disease and 29 had a structurally normal heart. 10 subjects with structurally normal hearts and normal septal $q$ waves were taken as controls.
\end{abstract}

Results-The timing of left ventricular minor axis motion was consistently normal in patients with abnormal activation, but long axis motion was considerably altered, with delayed "post-ejection shortening" of a mean amplitude of 4 mm. The post-ejection shortening began $10(15) \mathrm{ms}$ and reached its peak $90(20) \mathrm{ms}$ after aortic closure $\left(A_{2}\right)$. Peak lengthening rate did not differ from normal $(6 \cdot 2$ (3.5) $v 8.5(3.5) \mathrm{cm} / \mathrm{s}$, NS) though it occurred significantly later. Post-ejection shortening was unrelated to age, amplitude of left ventricular wall motion, or QRS axis on the surface electrocardiogram. Post-ejection shortening was commoner when QRS duration was $>115 \mathrm{~ms}$, but an absent septal $q$ wave predicted its presence with a specificity of $90 \%$ and sensitivity of $86 \%$. In patients with a postejection shortening, the onset of left ventricular systolic long axis shortening was delayed and the extent of its lengthening during the pre-ejection period increased, indicating delayed and incoordinate onset of tension development. During diastole, post-ejection shortening was associated with a prolonged isovolumic relaxation period and the time from $A_{2}$ to the onset of transmitral flow. Peak mitral $E$ wave flow velocity was reduced due to a fall in acceleration time although acceleration rate itself was unchanged.

Conclusion-Loss of the normal septal q wave is associated with considerable mechanical consequences throughout the cardiac cycle, from the pre-ejection period to atrial systole, and apparently causes asychronous subendocardial function.

\section{(Br Heart f 1994;72:45-51)}

The initial component of the normal QRS complex is directed anteriorly and to the right. It was ascribed by $\mathrm{Sir}$ Thomas Lewis to early activation of the left side of the intraventricular septum over 70 years ago, ${ }^{1}$ and in the left chest leads is still generally known as the septal $\mathrm{q}$ wave. Insofar as it has any accepted clinical significance, its presence is a minor criterion of normality, ${ }^{2}$ and its absence a feature distinguishing non-specific intraventricular conduction delay from classic left bundle branch block. ${ }^{3}$ Absence of a septal q wave may occur as an isolated abnormality in patients with increased myocardial fibrosis. ${ }^{4}$ It was the aim of this study to determine whether the septal $q$ wave was of any mechanical importance, either in isolation or associated with increased QRS duration. As subendocardial fibres are arranged longitudinally, ${ }^{5}$ we chose to study the possible mechanical consequence of the presence or absence of presumed early septal activation in terms of long axis function of the two ventricles, to examine interrelations with broadening of the QRS complex, and to compare the results with a group of normal controls.

\section{Patients and methods \\ PATIENTS}

We studied 63 patients, selected on the basis of their resting electrocardiograms, to investigate the interrelations between QRS duration and the presence or absence of a septal $q$ wave. Twenty five had classic left bundle branch block ${ }^{3}$ - that is, a QRS duration of $>120 \mathrm{~ms}$, no secondary $\mathrm{R}$ wave in $\mathrm{V} 1$ or $\mathrm{V} 2$, and no $q$ wave in $V 5$ and V6. Eight had a QRS duration of $>100 \mathrm{~ms}$, our upper limit of the normal $95 \%$ confidence interval $(95 \%$ CI), but septal q waves were present. In 26 patients the QRS duration was $<120 \mathrm{~ms}$, but the septal q wave was absent in leads V5 and V6. In 15 of these patients it was also absent in leads I and a VL, and in 11 it was present. Most of the patients had overt left ventricular disease. Table 1 gives pathological data, and tables 2 and 3 give basic echocardiographic and demographic details. To determine $95 \%$ 
Table 1 General data of the patients

\begin{tabular}{|c|c|c|c|c|}
\hline $\begin{array}{l}\text { Electrocardiographic } \\
\text { features }\end{array}$ & Aetiology & $\begin{array}{l}\text { Sample } \\
\text { size }\end{array}$ & Age (yr) & $M / F$ \\
\hline $\begin{array}{l}\text { Classic left bundle } \\
\text { branch block }\end{array}$ & $\begin{array}{l}\text { Normal heart } \\
\text { Dilated cardiomyopathy } \\
\text { Ischaemic cardiomyopathy } \\
\text { Dilated LV after AVR }\end{array}$ & $\begin{array}{r}9 \\
10 \\
4 \\
2\end{array}$ & $36-75$ & $19 / 6$ \\
\hline Absent septal q waves & $\begin{array}{l}\text { Normal heart } \\
\text { Ischaemic cardiomyopathy } \\
\text { Dilated LV after AVR }\end{array}$ & $\begin{array}{r}20 \\
3 \\
3\end{array}$ & $26-76$ & $19 / 7$ \\
\hline $\begin{array}{l}\text { Normal septal q } \\
\text { waves and QRS } \\
\text { duration } \geqslant 100 \mathrm{~ms}^{\star}\end{array}$ & Dilated cardiomyopathy & 8 & $36-73$ & $7 / 1$ \\
\hline $\begin{array}{l}\text { Normal septal q } \\
\text { waves and normal } \\
\text { QRS duration }\end{array}$ & Dilated cardiomyopathy & 4 & $25-70$ & $4 / 0$ \\
\hline
\end{tabular}

*one patient had QRS duration $>120 \mathrm{~ms}$. AVR, aortic valve replacement; $\mathrm{LV}$, left ventricle.

Table 2 Comparison of mean (SD) measurements of the left ventricle between patients with and without post ejection shortening

\begin{tabular}{llll}
\hline Measurement & $\begin{array}{l}\text { Controls } \\
(n=10)\end{array}$ & $\begin{array}{l}\text { No PES } \\
(n=13)\end{array}$ & $\begin{array}{l}\text { PES } \\
(n=50)\end{array}$ \\
\hline Age (yr) & $47(16)$ & $58(11)$ & $59(10)$ \\
M/F (n) & $6 / 4$ & $11 / 2$ & $37 / 13$ \\
RR interval (ms) & $850(170)$ & $700(110)$ & $750(135)$ \\
PR interval (ms) & $162(20)$ & $161(20)$ & $183(25)^{\star \star}+\dagger$ \\
QRS duration (ms) & $86 \cdot 5(7 \cdot 5)$ & $115(19)^{\star \star}$ & $125(28)^{\star \star}$ \\
QRS axis (degrees) & $35(45)$ & $-15(50)^{\star}$ & $-20(35)^{\star}$ \\
Left ventricular end diastolic dimension (cm) & $4 \cdot 9(0 \cdot 5)$ & $6 \cdot 7(1 \cdot 1)^{\star \star}$ & $6 \cdot 3(1 \cdot 4)^{\star \star}$ \\
Q to onset of left lateral wall shortening (ms) & $105(8 \cdot 0)$ & $120(25)$ & $135(25)^{\star \star}$ \\
Q to onset of long axis septal shortening (ms) & $102(7 \cdot 5)$ & $115(24)$ & $120(23)^{\star}$ \\
A2 to mitral opening (ms) & $55(10)$ & $40(20)$ & $75(28)^{\star \star}+\dagger$ \\
A2 to onset of mitral flow (ms) & $83(15)$ & $70(18)$ & $112(35)^{\star \star}+\dagger$ \\
Peak velocity of mitral E wave (m/s) & $0 \cdot 74(0 \cdot 18)$ & $0 \cdot 90(0 \cdot 28)$ & $0 \cdot 51(0 \cdot 22)^{\star \star}+t$ \\
Acceleration time of mitral E wave (ms) & $65(15)$ & $70(30)$ & $45(30) \dagger$ \\
Acceleration rate of mitral E wave (G) & $1 \cdot 3(0 \cdot 5)$ & $1 \cdot 65(0 \cdot 9)$ & $1 \cdot 7(2 \cdot 0)$ \\
Peak velocity of mitral A wave (m/s) & $0 \cdot 48(0 \cdot 14)$ & $0.36(0 \cdot 16)$ & $0 \cdot 67(0 \cdot 20)^{\star \star}+\dagger$ \\
\hline
\end{tabular}

${ }^{\star} \mathrm{p}<0.05 ;{ }^{\star \star} \mathrm{p}<0.01 v$ normal; tp $<0.05 ;$ ttp $<0.01 v$ patients without post-injection shortening (PES).

Table 3 Comparison of digitised $M$ mode echocardiographic mean (SD) measurements

\begin{tabular}{|c|c|c|c|}
\hline Measurement & Controls & No PES & PES \\
\hline $\begin{array}{l}\text { Peak rate of left posterior wall thinning }(\mathrm{cm} / \mathrm{s}) \\
\text { Peak mitral E wave to end of posterior wall } \\
\text { rapid thinning (ms) }\end{array}$ & $\begin{array}{l}5 \cdot 8(2 \cdot 4) \\
30(30)\end{array}$ & $\begin{array}{c}4 \cdot 9(3 \cdot 3) \\
50(65)\end{array}$ & $\begin{array}{l}5 \cdot 1(2 \cdot 3) \\
58(55)\end{array}$ \\
\hline $\begin{array}{l}\text { Peak rate of left lateral wall shortening }(\mathrm{cm} / \mathrm{s}) \\
\text { Peak rate of left lateral wall lengthening }(\mathrm{cm} / \mathrm{s}) \\
\text { Peak rate of septal shortening }(\mathrm{cm} / \mathrm{s}) \\
\text { Peak rate of septal lengthening }(\mathrm{cm} / \mathrm{s}) \\
A_{2} \text { to Peak rate of septal lengthening }(\mathrm{ms})\end{array}$ & $\begin{array}{r}7 \cdot 3(2 \cdot 4) \\
9 \cdot 3(4 \cdot 0) \\
7 \cdot 1(3 \cdot 5) \\
8 \cdot 7(3 \cdot 0) \\
115(25)\end{array}$ & $\begin{array}{l}4 \cdot 8(2 \cdot 1)^{\star} \\
8 \cdot 3(4 \cdot 0) \\
3 \cdot 5(2 \cdot 0)^{\star \star} \\
4 \cdot 7(3 \cdot 0)^{\star} \\
123(35)\end{array}$ & $\begin{array}{l}5 \cdot 5(2 \cdot 5)^{\star} \\
6 \cdot 9(3 \cdot 5) \\
3 \cdot 7(1 \cdot 5)^{\star \star} \\
6 \cdot 2(3 \cdot 5) \\
169(35)^{\star \star}+\dagger\end{array}$ \\
\hline $\begin{array}{l}\text { Left } \\
\text { Septum } \\
\text { Right }\end{array}$ & $\begin{array}{l}-6 \cdot 0(11) \\
-7 \cdot 0(15) \\
-4 \cdot 0(15)\end{array}$ & $\begin{array}{l}-3 \cdot 5(12) \\
-2 \cdot 5(20) \\
-17(21)\end{array}$ & $\begin{aligned} & 6 \cdot 0(25) \\
- & 10(25) \\
- & 27(21)^{\star} \dagger\end{aligned}$ \\
\hline $\begin{array}{l}\text { Long axis dimension change during IVR (\%): } \\
\text { Left } \\
\text { Septum } \\
\text { Right }\end{array}$ & $\begin{array}{l}4 \cdot 5(4 \cdot 0) \\
2 \cdot 3(9 \cdot 0) \\
5 \cdot 5(5 \cdot 0)\end{array}$ & $\begin{array}{r}4.0(14) \\
-4 \cdot 0(18) \\
4.5(8 \cdot 0)\end{array}$ & $\begin{aligned} & 2 \cdot 0(16) \\
- & 17(15)^{\star} \dagger \\
& 11(11)^{\star} \dagger\end{aligned}$ \\
\hline
\end{tabular}

shortening (PES); PEP, pre-ejection period; IVR, isovolumic relaxation period.

CIs, we also studied 10 patients of similar age range (23-68 years) with structurally normal hearts and $\mathrm{q}$ waves present in leads $\mathrm{V} 5$ and V6, selected from patients referred for echocardiographic examination, with a number of minor cardiological symptoms including atypical chest pain, systolic murmur, and breathlessness.

\section{ELECTROCARDIOGRAPHY}

We recorded 12 lead standard surface electrocardiograms with a Hewlett Packard $\mathrm{XLi}$ PageWriter Cardiograph, at a paper speed of 25 or $50 \mathrm{~mm} / \mathrm{s}$ and a filter of $0.05-100 \mathrm{~Hz}$.
Built in software calculated and printed PR interval, QRS duration, and axis. Complete absence of a septal $q$ wave was diagnosed when there were no q waves in lead I, AVL, V5 and V6; and partial absence of septal q wave when there were $q$ waves in leads $I$ and aVL but not in V5 and V6.

\section{ECHOCARDIOGRAPHY AND PULSED DOPPLER} RECORDINGS

Immediately before or after the electrocardiogram, cross sectionally guided multiple $M$ mode echocardiograms were photographically recorded with simultaneous lead II electrocardiogram and phonocardiogram, at a paper speed of $100 \mathrm{~mm} / \mathrm{s}$. We recorded short axis $M$ mode echograms of the left ventricle at the mitral valve tip and at the aortic valve levels. We also recorded long axis echocardiograms of left, septal, and right sites on the atrioventricular junction. ${ }^{6}$ The aortic component of the second heart sound $\left(A_{2}\right)$ was identified from the aortic echogram and was used to time the onset of left ventricular diastole.

The $M$ mode echograms were digitised with time markers. ${ }^{7}$ The following measurements were made.

(a) End diastolic dimension coincident with the $Q$ wave of the electrocardiogram and end systolic dimensions of the left ventricle coincident with $\mathrm{A}_{2}$.

(b) Isovolumic relaxation time from $A_{2}$ to the onset of mitral cusp separation.

(c) Time of onset of systolic regional wall motion relative to that of the QRS complex.

(d) Peak rates of shortening and lengthening in all sites of the long and short axes.

(e) Time intervals from $A_{2}$ to peak lengthening rate in the long axis and the end of rapid posterior wall thinning in the short axis.

$(f)$ Incoordinate wall motion defined as longitudinal or transverse dimension changes during isovolumic contraction and relaxation periods relative to total dimension change in the same cardiac cycle. ${ }^{8}$

Transmitral flow velocities were recorded with pulsed Doppler at the level of valve tips, again with simultaneous electrocardiogram and phonocardiogram at a paper speed of 100 $\mathrm{mm} / \mathrm{s}$. From these traces we measured:

(a) times from $\mathrm{A}_{2}$ to the onset and the peak of mitral early diastolic flow ( $\mathrm{E}$ wave);

(b) peak velocities of $\mathrm{E}$ wave and $\mathrm{A}$ wave (atrial systolic mitral flow);

(c) acceleration time from the onset to the peak of the $\mathrm{E}$ wave;

(d) mean acceleration rate of early diastolic flow as peak velocity divided by acceleration time.

\section{STATISTICAL ANALYSIS}

Measurements were taken from the average of three successive heart beats. Overall values are expressed as group mean (SD). Unpaired Student's $t$ test and analysis of variance were used to assess the differences between groups. The $\chi^{2}$ or Fisher's exact probability test were used to examine differences in incidence. To assess the effects of QRS duration among the groups, the median value $(115 \mathrm{~ms})$ was used. 
Table 4 Effects of abnormal activation on mean (SD) left ventricular minor axis motion

\begin{tabular}{|c|c|c|c|c|}
\hline \multirow[b]{2}{*}{ Variable } & \multicolumn{2}{|c|}{ Septal q wave } & \multicolumn{2}{|c|}{ QRS duration } \\
\hline & Absent & Present & $\geqslant 115 \mathrm{~ms}$ & $<115 \mathrm{~ms}$ \\
\hline $\begin{array}{l}\text { Left ventricular end diastolic } \\
\text { dimension }(\mathrm{cm})\end{array}$ & $6.4(1.4)$ & $6 \cdot 4(1 \cdot 3)$ & $6.6(1.3)$ & $6 \cdot 1(1 \cdot 3)$ \\
\hline $\begin{array}{l}\text { Shortening fraction (\%) } \\
\text { Peak rate of dimension } \\
\text { decrease }(\mathrm{cm} / \mathrm{s})\end{array}$ & $\begin{array}{l}20(8 \cdot 0) \\
6 \cdot 8(2 \cdot 9)\end{array}$ & $\begin{array}{l}23(8 \cdot 0) \\
8 \cdot 0(3 \cdot 0)\end{array}$ & $\begin{array}{l}20(8 \cdot 0) \\
6 \cdot 5(3 \cdot 0)\end{array}$ & $\begin{array}{l}23(9 \cdot 0) \\
7 \cdot 5(2 \cdot 7)\end{array}$ \\
\hline Peak rate of dimension & $9 \cdot 0(4 \cdot 5)$ & $10.5(5.0)$ & $9 \cdot 0(4 \cdot 5)$ & $9.8(4.5)$ \\
\hline $\mathrm{A}_{2}$ to peak rate of dimension & $105(45)$ & $90(30)$ & $110(35)$ & $100(45)$ \\
\hline $\begin{array}{l}\text { Peak rate of posterior wall } \\
\text { thickening }(\mathrm{cm} / \mathrm{s})\end{array}$ & $3 \cdot 1(1 \cdot 1)$ & $3.1(1.4)$ & $3 \cdot 2(1 \cdot 2)$ & $3.0(1 \cdot 1)$ \\
\hline $\begin{array}{l}\text { Peak rate of posterior wall } \\
\text { thinning }(\mathrm{cm} / \mathrm{s})\end{array}$ & $5 \cdot 0(2 \cdot 2)$ & $5.0(3.3)$ & $5.0(2.4)$ & $5 \cdot 1(2 \cdot 6)$ \\
\hline $\begin{array}{l}\mathrm{A}_{2} \text { to peak rate of posterior } \\
\text { wall thinning (ms) }\end{array}$ & $105(50)$ & $105(50)$ & $110(60)$ & $105(40)$ \\
\hline
\end{tabular}

No difference in any measurement between patients with presence or absence of septal $q$ wave or patients with QRS duration $\geqslant 115 \mathrm{~ms}$ or $<115 \mathrm{~ms}$ was significant.

\section{Results}

LEFT VENTRICULAR MINOR AXIS MOTION

Neither abnormal activation assessed as QRS duration above or below the median value of $115 \mathrm{~ms}$ nor the presence or absence of the septal q wave affected conventional measurements of left ventricular minor axis motion (table 4).
LEFT VENTRICULAR LONG AXIS MOTION

Long axis motion was consistently altered in patients with abnormal activation whether or not structural heart disease was present. After aortic valve closure, further abnormal long axis shortening, outside the normal $95 \% \mathrm{CI}$, occurred in the septum (33 patients), left lateral wall (two patients), or both (15 patients), by a mean amplitude of $4 \mathrm{~mm}$. It began 10 (15) $\mathrm{ms}$ and reached its peak 90 (20) $\mathrm{ms}$ after $A_{2}$. Peak lengthening rate thereafter was $6 \cdot 2$ (3.5) $\mathrm{cm} / \mathrm{s}$, not significantly different from normal 8.5 (3.5), although it -was registered significant later. Maximum shortening followed mitral cusp separation by $25 \mathrm{~ms}$, but preceded the onset of mitral flow by a mean time of $10 \mathrm{~ms}$. In view of these time relations, we use the term "post-ejection shortening" to describe the abnormal shortening of the long axis after aortic valve closure (fig 1 ). It was not reflected on the minor axis, which showed effectively normal time relations with respect to the second heart sound and the transmitral flow velocity signal.

\section{CLINICAL ASSOCIATIONS OF POST-EJECTION} SHORTENING

Post-ejection shortening was seen in patients

\section{A}

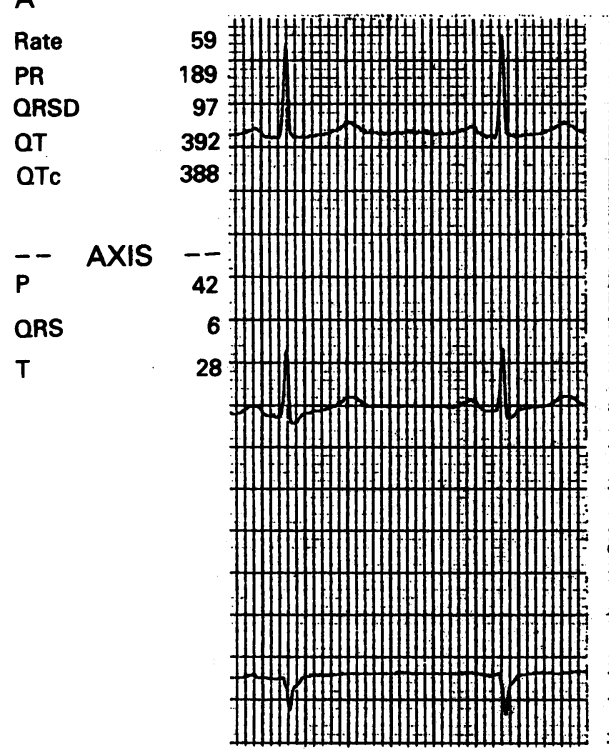

1 II III

B

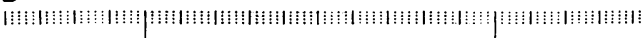
ECG

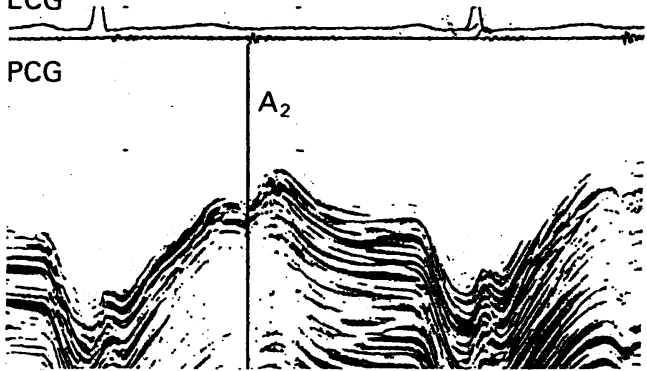

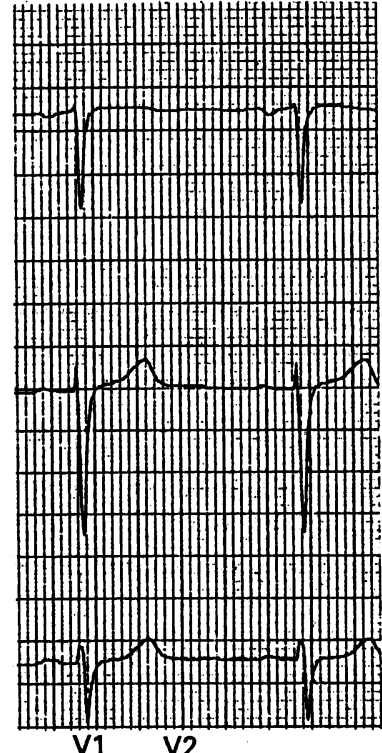

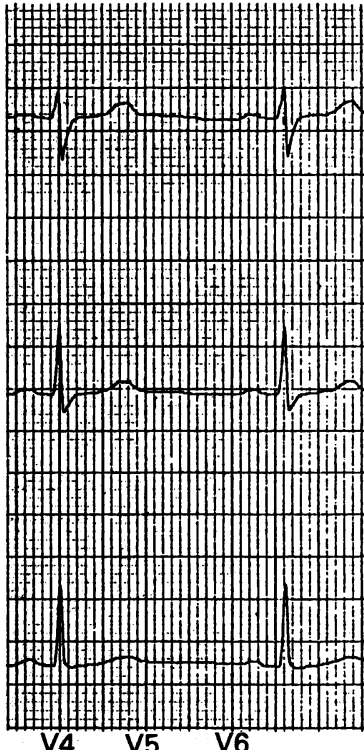

C

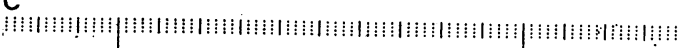

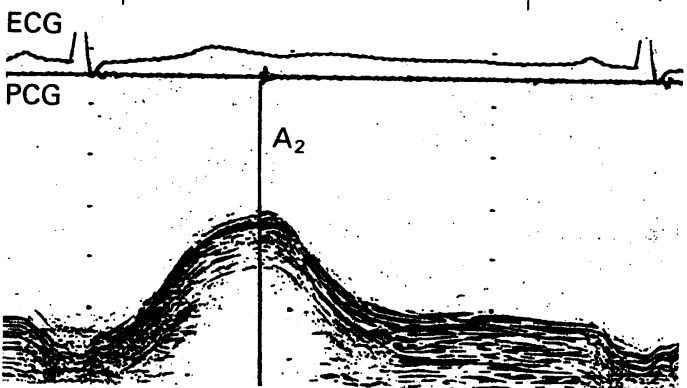

Figure 1 (A) Electrocardiogram and $(B)$ long axis $M$ mode echocardiogram of the interventricular septum were recorded in a 73 year old woman, who was referred to the cardiac clinic with breathlessness for six months and one episode of pulmonary oedema. She had a structurally normal heart and normal shortening fraction on echocardiography. Note that on the electrocardiogram there are no septal $q$ waves and on the echocardiogram there is considerable post-ejection shortening compared with (C) a control trace. (Depth scale $=1 \mathrm{~cm}$ ) 
Table 5 Correlation of $Q R S$ duration and the incidence of post-ejection shortening (PES) $(p<0.001)$

\begin{tabular}{lrl}
\hline & No PES & PES \\
\hline QRS duration $\geqslant 115 \mathrm{~ms}$ & 5 & 29 \\
QRS duration $<115 \mathrm{~ms}$ & 18 & 21 \\
\hline
\end{tabular}

Table 6 Correlation of absence of septal $q$ wave and the incidence of post-ejection shortening (PES) $(p<0.001)$

\begin{tabular}{lcc}
\hline & No PES & PES \\
\hline Absent septal q wave & $5(3)$ & $46(15)$ \\
Septal q wave & $19(14)$ & $3(2)$
\end{tabular}

Numbers in parentheses represent patients with a QRS duration of $<115 \mathrm{~ms}$.

with a normal left ventricle as well as those with an increased cavity size. Its presence was unrelated to age, amplitude of left ventricular wall motion, or the degree of left axis deviation of the QRS complex on the surface electrocardiogram. The QRS duration correlated with the incidence of post-ejection shortening in that it was much commoner with QRS values $>115$ ms (table 5, p $<0.001$ ). The corresponding value of specificity was $46 \%$ and sensitivity $85 \%$ for QRS duration in predicting the abnormality. Prolonged left ventricular activation is often associated with an absent septal q wave and the post-ejection shortening might thus be more closely related to this rather than the broad QRS complex itself. Table 6 shows that in the patients we studied, an absent septal $\mathrm{q}$ wave is indeed a more powerful predictor of post-ejection shortening with a specificity of $90 \%$ and sensitivity of $86 \%$. This relation holds even when patients with QRS duration above the median value are excluded (table 6 ).

ALTERED VENTRICULAR FUNCTION ASSOCIATED WITH POST-EJECTION SHORTENING

Tables 2 and 3 show that post-ejection shortening was not an isolated disturbance of ventricular wall motion. Although no significant differences in minor axis function could be identified, we noted a consistent increase in the time interval from the $Q$ wave of the electrocardiogram to the onset of left ventricular long axis shortening. Peak rates of longitudinal lengthening and shortening were similar in

Table 7 Comparison of mean (SD) measurements in patients with a QRS duration $<115 \mathrm{~ms}$

\begin{tabular}{lccl}
\hline Measurement & No PES & PES & P Value \\
\hline Age (y) & $57(17)$ & $59(20)$ & NS \\
Left ventricular end diastolic dimension (cm) & $6.5(0 \cdot 8)$ & $6 \cdot 0(1 \cdot 3)$ & NS \\
QRS duration (ms) & $104(7.0)$ & $100(10)$ & NS \\
Q to onset of left lateral wall motion (ms) & $110(7.5)$ & $125(14)$ & $<0.01$ \\
Q to onset of long axis septal motion (ms) & $110(15)$ & $115(15)$ & NS \\
A to onset of mitral flow (ms) & $75(20)$ & $110(30)$ & $<0.001$ \\
A to mitral opening (ms) & $40(20)$ & $80(25)$ & $<0.001$ \\
Peak velocity of mitral E wave (m/s) & $0 \cdot 80(0.25)$ & $0.50(0 \cdot 26)$ & $<0.01$ \\
Peak velocity of mitral A wave (m/s) & $0.38(0.15)$ & $0.61(0 \cdot 19)$ & $<0.05$ \\
Long axis dimension change during PEP (\%): & $-3.5(13)$ & $8.5(25)$ & NS \\
$\quad$ Left & $1.0(18)$ & $-4.5(25)$ & NS \\
Septum & $-13(18)$ & $-15(20)$ & NS \\
Right & $0(9.0)$ & $-1.0(18)$ & NS \\
Long axis dimension change during IVR (\%): & $0 \cdot 2(6.5)$ & $-16(19)$ & $\star$ \\
$\quad$ Left & $3.5(6.5)$ & $10(10)$ & NS \\
Septum &
\end{tabular}

*Significant by definition. Numbers in parentheses represent patients with a QRS duration of $<115 \mathrm{~ms}$.

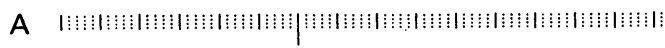

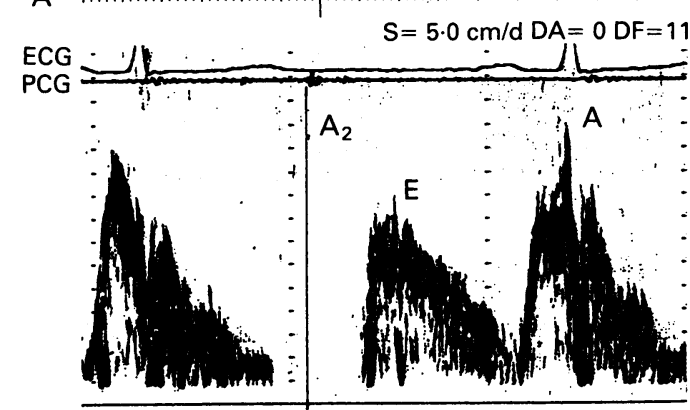

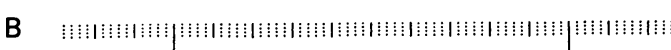
$S=12.5 \mathrm{~cm} / \mathrm{d} D A=0 \mathrm{DF}=11$

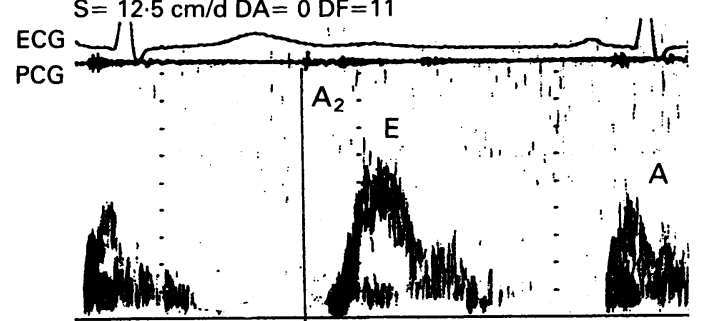

Figure 2 Pulsed Doppler traces of transmitral flow recorded in $(A)$ the patient and $(B)$ a control (as in fig 1), showing the obvious differences in the time from $A$ to the onset of mitral flow, and the velocities of $E$ and $A$ waves.

both ventricular long axes, whether or not post-ejection shortening was present. The free wall of the right ventricle did not show postejection shortening in any patient. Instead, it shortened strikingly during the left ventricular pre-ejection period and lengthened during isovolumic relaxation.

During diastole, isovolumic relaxation time and the interval from $A_{2}$ to the onset of transmitral flow were both significantly longer in patients with post-ejection shortening (tables 2 and 3 ). The peak velocity of early diastolic flow into the left ventricle ( $E$ wave) was nearly half the value found in patients without postejection shortenings, although the timing of peak velocity itself was unchanged with respect to $A_{2}$ (tables 2 and 3, fig 2). This means that acceleration time was shortened in the patients with post-ejection shortening, and indeed, it was this reduction, rather than any fall in acceleration of blood flow that was responsible for the lower peak inflow velocity. The relation of peak $\mathrm{E}$ wave to the end of rapid wall thinning was unchanged (tables 2 and 3 ).

These associations persisted even in the subgroup of patients with a QRS duration of $<115 \mathrm{~ms}$, the overall median value (table 7). In patients in whom post-ejection shortening was present, the onset of left lateral long axis shortening was significantly delayed by $15 \mathrm{~ms}$ with respect to the onset of the QRS complex. Mitral cusp separation and the onset of transmitral flow were delayed by $30 \mathrm{~ms}$ with respect to $A_{2}$; the amplitude of the $E$ wave was again reduced and that of the $A$ wave increased.

EFFECT OF THE EXTENT OF LOSS OF THE SEPTAL Q WAVE

The effect of the extent of loss of the septal $q$ wave was investigated by comparing patients 
in whom the septal $\mathrm{q}$ wave was absent from both precordial and limb leads with those in whom it was absent from precordial leads only. The QRS duration was significantly longer in the group in which the septal q wave was totally absent (130 (29) ms v 112 (20), $p<0.01)$. Partial and complete loss of the septal $q$ wave proved equally effective in predicting the presence of a post-ejection shortening. Any differences between the two groups seemed small; the only one to reach significance was that in which the time interval from the onset of the QRS complex to that of transverse septal shortening was reduced with complete loss of the septal q wave (48 (15) ms), but not when it was partial (60 (15) $\mathrm{ms})$.

\section{Discussion}

A normal ventricular contraction implies an orderly sequence of tension development in different regions of the myocardium. This requires a correspondingly organised process of activation. Although the potential importance of activation as a main determinant of ventricular function has been stressed in the past, ${ }^{9}$ such electromechanical interactions have received little attention recently compared with that bestowed upon entities such as contractility, and more recently, relaxation. Nevertheless, there are data already available in experimental animals ${ }^{9}$ and humans ${ }^{10-12}$ to suggest that activation may have significant effects on the subsequent contraction pattern. The present investigation aimed to extend these studies by examining the specific associations of loss of the septal $q$ wave on the subsequent pattern of ventricular wall motion and to trace its influence beyond systole to the processes of relaxation, rapid ventricular filling, and even atrial systole. We chose to study possible influence of losing the septal q wave as this electrical event is widely believed to reflect the earliest stage of ventricular activation. ${ }^{13-15}$ It thus seemed a logical place to start investigating electromechanical function.

It is well recognised that the septal $q$ wave is often lost when left ventricular activation is abnormal and indeed its loss is one of the main criteria by which the pattern of classical left bundle branch block is recognised. ${ }^{3}$ This association accounted for most of the instances in our study. It became apparent, however, that the two abnormalities could be dissociated. In dilated cardiomyopathy, for example, considerable prolongation of the QRS complex can occur with the septal $q$ wave preserved. In other patients, the septal q wave was lost although the QRS duration was considerably less than the $120 \mathrm{~ms}$ necessary for a diagnosis of left bundle branch block, and we even identified patients in whom QRS duration was within normal limits. Further, in some cases, the septal $\mathrm{q}$ wave was lost both in limb leads and lateral chest leads, whereas in the others, the loss was only confined to the lateral leads. Our study was therefore designed to take advantage of this diversity. We were able to compare the electromechani- cal associations of isolated loss of the septal $q$ wave with isolated prolongation of activation and the combination of the two.

Our most consistent finding was a disturbance of left ventricular long axis function. The most obvious feature of this was continued shortening after aortic valve closure-that is, during the period of isovolumic relaxation. This continued shortening was separated from that normally occurring during systole by a brief period of lengthening (fig 1). It started 10-15 ms after the end of ejection, and reached its peak about $90 \mathrm{~ms}$ later. It was most commonly seen on the septal long axis, and in about one third of the cases also on the lateral left ventricular wall. In only two cases, was the ventricular wall alone involved. The right ventricle was never affected. The sensitivity of a prolonged QRS complex was similar to that of loss of the septal q wave in predicting this abnormality, but the specificity of an absent septal $\mathrm{q}$ wave was much greater than that of a prolonged QRS complex. Indeed, the apparent sensitivity of increased QRS duration as a predictor of the long axis disturbance merely reflected its association with loss of the septal $\mathrm{q}$ wave in patients with the electrocardiographic pattern of classical left bundle branch block. The mechanical concomitants of loss of the q wave in chest and limb leads were so similar to those of its loss in chest leads alone that the two electrocardiographic patterns seem to be different manifestations of the same fundamental disturbance. It was striking that whereas the long axis abnormalities were obvious on simple inspection, disturbances of the more commonly studied minor axis were inconspicuous.

The relation between loss of the septal $q$ wave and abnormal wall motion was so close as to raise the possibility that the one is the direct cause of the other. We have previously suggested, on the basis of dissection, that subendocardial muscle fibres within the left ventricle are longitudinally directed. ${ }^{5}$ Further, the earliest portion of the ventricular myocardium to become activated is the subendocardium of the septum and lateral wall at mid-cavity level. ${ }^{1}$ Post-ejection shortening itself occurs during isovolumic relaxation, when ventricular pressure is greater than that in the left atrium, so it is likely to be the result of active, although declining, contraction where the overall sequence has been delayed by abnormal septal activation. Even more direct evidence that this occurs is the consistent delay in the onset of shortening of the lateral left ventricular wall with respect to the electrocardiogram. The normal peak shortening rate makes it very unlikely that both electrical and mechanical disturbances are direct results of systolic disease. By the same token, the normal diastolic lengthening rate after the second peak would seem to exclude a primary disturbance of relaxation such as has been invoked in patients with left ventricular hypertrophy ${ }^{16}$ or coronary artery disease. ${ }^{17} \mathrm{We}$ conclude, therefore, that absence of the septal $q$ wave is a marker of abnormal activation of the left ventricular 
subendocardium, and that this disturbance was the direct cause of the altered pattern of long axis motion that we found.

These disturbances of systolic wall motion were associated with a series of alterations in diastolic function. Isovolumic relaxation time and the interval from aortic closure to the onset of transmitral flow were both prolonged; the peak velocity of early diastolic transmitral flow was reduced, and that of atrial systole increased. These associations are likely to have been due to prolongation of the development of subendocardial myocardial tension that reduced the rate of fall of left ventricular pressure, and thus delayed the onset of filling. Although there was a small increase in the mean increase of transverse dimension during isovolumic relaxation, this did not occur consistently. We found interrelations between wall motion and the $E$ wave on the transmitral Doppler recording. The peak velocity was reduced because the acceleration time was reduced, not because of any differences in early acceleration itself (fig 2 ); indeed values were effectively identical to normal, whether or not a septal q wave was present. The timing of the $E$ wave itself with respect to $A_{2}$, and also to the end of rapid thinning of the posterior wall was unaltered. We had anticipated that prolonged relaxation in one region of the ventricle would reduce the early diastolic left ventricular to left atrial pressure gradient, which represents the force causing the early diastolic acceleration of blood across the mitral valve. Rather surprisingly, this did not seem to be the case. Instead, prolonged long axis shortening delayed the onset of transmitral flow, but once the transmitral flow began it seemed to be subject to the same forces and thus the same acceleration as in the controls. This unexpected finding would, however, be compatible with our previous finding that early acceleration of blood across the mitral valve is synchronous with rapid thinning of the left ventricular free wall, ${ }^{18}$ which provides the underlying forces. Rapid thinning is due to elastic forces and is independent of the relaxation process. It should not, therefore, be altered by the changes in wall movement in our patients. By considering the two components of peak velocity separately, therefore, the effect of delayed onset of filling could be dissociated from a reduction in early diastolic atrioventricular forces, allowing the underlying mechanisms to be isolated.

This study has a number of possible technical limitations. The septal $q$ wave has received so little detailed study that well defined criteria for normality do not exist. It is essential that the electrocardiograph used to detect it has an adequate frequency response. The septal $q$ wave may be lost with extreme clockwise rotation, even in an otherwise normal heart. ${ }^{2}$ Its absence often coexists with other disturbances of activation that are known to be associated with prolongation of mechanical systole and disturbed diastolic function, so it was necessary to dissociate the two effects. In our study, we have shown an association only between loss of the septal $\mathrm{q}$ wave and an abnormal contraction pattern. We were unable to modify the activation pattern directly, so that a causal relation must remain a deduction. We did not aim to undertake an epidemiological study. Patients with isolated absence of the septal $q$ wave were identified from those studied in a clinical echocardiographic department. Even when patients can be shown to have no obvious structural heart disease, they cannot necessarily be regarded as completely normal, and indeed, often arrive with a series of cardiological diagnoses ranging from "soft systolic murmur" to "heart failure". For this reason, our controls were taken from the same population, differing only insofar as their resting electrocardiograms were also normal. Our study was not designed to determine whether isolated loss of the septal $q$ wave has any recognisable clinical consequences; to settle this question would need a quite different approach.

Our study provides further evidence of the predictable and important interrelations between electrical and mechanical events in the human left ventricle. An absent septal q wave has mechanical consequences throughout the cardiac cycle from the pre-ejection period to atrial systole. The nature of these relations was implicit in work done decades ago, yet seldom considered by cardiologists or clinical physiologists today. Disturbances of ventricular filling are often taken as evidence of abnormalities of ventricular compliance ${ }^{19}$ or relaxation, ${ }^{20}$ yet in the patients we studied, the origin of disturbances of ventricular filling could be seen to arise much earlier in the cardiac cycle, not just in systole, but in activation. Our findings seem to have a number of practical consequences, and go some way to explaining the well known deterioration of diastolic as well as systolic ventricular function that accompanies left bundle branch block. The effects of activation on left ventricular long axis function must be known when it is studied in patients suspected of having coronary artery disease.$^{17}$ In showing that the effects of disturbed activation extend beyond systole, it is not difficult to imagine that electrophysiological methods might be devised to correct them and so treat disturbances of diastolic function, a field where the success of pharmacology has been very limited.

HBX is supported by the Royal Brompton Hospital Special Cardiac Fund.

1 Lewis $T$. The spread of the excitatory process in the vertebrate heart. Parts I-V. Philosophical Transactions of the Royal Society of London 1916;207-B:221-310.

2 Rowlands DJ. Normal electrocardiographic appearances. In: Rowlands DJ, ed. Clinical Electrocardiography. London: Gower Medical Publishing, 1991;29-61.

3 Willems JL, de Medina EOR, Berard R, Coumel P, Fisch $\mathrm{C}$, Krikler $\mathrm{D}$, et al. Criteria for intraventricular conduction disturte al. Crites and pre-excitation. $₹ \mathrm{Am}$ Coll Cardiol 1985;5:1261-75.

4 Burch GE, DePasquale N. A study at autopsy of the relation of absence of the $Q$ wave in leads $I$, avL, V5 and V6 to septal fibrosis. Am Hear $\mathcal{F} 1960 ; 60: 336-40$.

5 Greenbaum RA, Ho SY, Gibson DG, Becker AE, Anderson RH. Left ventricular fibre architecture in man. Br Heart $\mathcal{F} 1981 ; 45: 248-63$.

6 Jones CJH, Raposo L, Gibson DG. Functional importance of the long axis dynamics of the human left ventricle. $\mathrm{Br}$ of the long axis dynamics

7 Upton MT, Gibson DG. The study of left ventricular 
function from digitised echocardiograms. Prog Cardiovasc Dis 1978;20:359-84.

8 Gibson DG. Study of incoordinate left ventricular contraction by echocardiography. In: Bleifeld W, Effert $S$, Hanrath P, Mathey D, eds. Evaluation of cardiac function by echocardiography. Berlin: Springer-Verlag, 1980: 57-64.

9 Wiggers CJ. Are ventricular conduction changes importan in dynamics of ventricular contraction? $A m \mathcal{F}$ Physio 1926;74:12-30.

10 Gibson DG, Chamberlain DA, Coltart DJ, Mercer J Effect of changes in ventricular activation on cardiac haemodynamics in man. Comparison of right ventricular, left ventricular and simultaneous pacing of both ventricles. Br Heart $\mathcal{f}$ 1971;33:397-400.

11 Gibson DG. Disordered left ventricular contraction associated with abnormalities of conduction. Postgrad Med $\mathcal{F}$ 1972;48:756-9.

12 McDonald IG. Echocardiographic demonstration of abnormal motion of the interventricular septum in left bundle branch block. Circulation 1973;48:272-80.

13 Durrer D, van Dam T, Freud GE, Janse MJ, Meijler FL Arzbaecher RC. Total excitation of the isolated human Arzbaecher RC. Total excitation of

14 Scher AM, Young AC, Malmgren AL, Erickson RV.
Activation of the interventricular septum. Circ Res 1955; 3:56-64.

15 Rodriguez MI, Sodi-Pallares D. The mechanism of complete and incomplete bundle branch block. Am Heart $\mathcal{f}$ 1952;44:715-46.

16 Henein MY, Xiao HB, Brecker SJD, Gibson DG. The Bernheim A wave:obstructed right ventricular inflow or atrial crosstalk? Br Heart $\mathcal{f}$ 1993;69:409-13.

17 Henein MY, Priestley K, Davarashvili T, Buller N, Gibson DG. Early changes in left ventricular subendocardial function after successful coronary angioplasty. $\mathrm{Br} \mathrm{Heart}$ ₹ 1993;69:501-6.

18 Park CH, Chow WH, Gibson DG. Phase differences between left ventricular wall motion and transmitral flow in man: evidence for involvement of ventricular restoring forces in normal filling. Int $f$ Cardiol 1989;24:347-54.

19 Thomas JT, Choong CYP, Flachskampf FA, Weyman AE Analysis of the early transmitral Doppler velocity curve: effect of primary physiologic changes and compensatory preload adjustment. $\mathcal{A}$ Am Coll Cardiol 1990;16:644-55.

20 Mulvagh S, Quinones MA, Kleiman NS, Cherif BJ, Zoghbi WA. Estimation of left ventricular end-diastolic pressure from Doppler transmitral flow velocity in carpressure from Doppler transmitral flow velocity in carColl Cardiol 1992;20:112-9. 